The effect of inbreeding on the early performance ... (Imron)

\title{
THE EFFECT OF INBREEDING ON THE EARLY PERFORMANCE OF FRESHWATER PRAWN, Macrobrachium rosenbergii
}

\author{
Imron \# \\ Research Institute for Fresh Water Fish Breeding and Aquaculture, \\ Sukamandi, Subang, West J ava, Indonesia
}

\begin{abstract}
Inbreeding depression has often been considered to be responsible for the deterioration of performance in aquaculture species. Despite a crucial impact that may result from inbreeding depression, comprehensive information reviewing this subject is limited. This study was aimed to gain information on the effect of inbreeding on the early performance of freshwater prawn. The study was performed by comparing performance of inbred and outbred populations. Inbred population was established by brother-sister mating (inbreeding rate of $25 \%$ while the outbred population was formed by mating unrelated individuals. Several fitness and productivity related traits including survival, the rate of larval development, stage dispersion and growth of larvae were evaluated. Results suggest that inbred families performed poorer than that of the outbred in survival. However, inbreeding depression did not seem to occur in other traits including the rate of larval development, larval stage dispersion and growth. This study implies that to maintain genetic quality of farmed prawn stocks, inbreeding rate in farmed population must be controlled not to exceed that level. Implications that these findings may have on aquaculture practices and possible alternatives for the solutions are discussed.
\end{abstract}

KEYWORDS: inbreeding, larval performance, freshwater prawn

\section{INTRODUCTION}

Inbreeding, the mating among closely related individuals, has often been considered to be responsible for the deterioration in productivity performance of aquaculture species due to inbreeding depression (Tave, 1999). This problem particularly occurs for aquaculture species where broodstcoks are derived from captivity. Hence, this issue has been of a great concern for aquaculture species such as trout, Oncorhynchus myskiss, (Su et al., 1996) tilapia (Osure and Phelps, 2006), common carp, and freshwater prawn (Ahmed et al., 2008).

In contrast to penaeid prawn, particularly Penaeus monodon, where broodstock supply for hatchery operation relies heavily on natural sources, most hatchery managers of freshwater prawn rely their broodstock supply from farmed stocks (Ahmed et al., 2008; New, 2002). This practice is mainly driven by at least two reasons. Firstly, it is relatively easier to supply a certain number of brooders from growing ponds compared to those obtained from natural waters where season influences the abundance. Secondly, reproductive performance of farmed broodstocks tend to be better than those obtained form natural waters (Bart \& Yen, 2003). Despite these advantages, fresh water prawn seeds derived from farmed broodstock are susceptible to the deterioration of genetic quality due to uncontrolled inbreeding rate resulted from

\# Corresponding author. Research Institute for Fresh Water Fish Breeding and Aquaculture (RIFFBA), PO Box 41256 Sukamandi, Subang, West Java, Indonesia, Indonesia. Tel.: +62 260520500

E-mail address: imronnawawi@yahoo.com 
the lack of appropriate broodstock management.

In general, hatchery owners used female gravid broodstok from grow- out ponds using phenotypic criteria, such as body length, body weight and maturity rate of gonad (New, 2002). Nearly no genetic considerations, such as pedigree information and effective breeding number producing the population of broodstock candidates, are taken into account. As a result, depending on the size of the ponds and stocking density applied, seed populations stocked into these ponds may be derived from only a few pair broodstocks. Consequently, inbreeding becomes unavoidable and depresses many phenotypic characters of economic importance.

While typical- adverse effects of inbreeding have been recognized, less detail information on the level of inbreeding that leads to inbreeding depression, as well as the type of phenotypic characters affected, are available (Tave, 1999). Previous studies suggested that in addition to the degree of inbreeding coefficient, the severity of inbreeding depression were also associated with many other factors such as ages, generations, families and species (Kincaid, 1983). In relation to developmental stage for instance, with the same inbreeding coefficient, the severity of inbreeding depression occurred in the early stage might not be similar to that occurred in the later stages (Theodorou \& Couvet, 2006).

Due to this specificity, results obtained from one study could not always be used to judge situation in other cases. This study was aimed to evaluate the effect of inbreeding on the early performance of fresh water prawn. Information gained from this study could be used to design a broodstock management strategy to avoid the occurrence of inbreeding depression.

\section{MATERIALS AND METHODS}

\section{Animal Test and Experimental Design}

The evaluation of inbreeding effect on several parameters of hatchery performances was performed by comparing the inbred and outbred populations. Inbred larval populations were obtained by hatching eye-spotted eggs incubated by gravid female broodstock with known pedigree from broodstock rearing ponds. As part of bigger work of selective breeding program, separate rearing ponds were used to raise a number of broodstock candidate originated from one family. Due to the same parental origin, gravid females obtained from this family were fertilized by their fullsib brothers. Consequently, the gravid females represented brother- sister mating. Under this condition, the resulting offsprings will have a minimum coefficient inbreeding of $25 \%$ The actual level of inbreeding coefficient may exceed this figure, depending on the relatedness of the ancestral lines.

Four gravid females, characterized by eyespotted egg mass incubated in their brood chambers, were taken from grow- out pond and incubated in 50-L conical hatching tanks equipped with gentle aeration. Following hatching, the spent broodstocks were removed from the tank and the newly hatched larvae were harvested using syphoning technique by allowing larvae to flow gravitationally through syphon pipe from conical tank to the larval collection chamber. The collected larvae were then disinfected by dipping them into a 200 ppm formaldehyde solution for 30 seconds.

Outbred population was formed by mating female broodstock drawn from one family with male from different family. For the purpose of calculation, inbreeding coefficient of the outbred was assumed and estimated to be zero. To perform this, females developing ovary development, characterized by the appearance of yellowish ovary on the carapace, were put in $1 \times 1 \mathrm{~m}$ square mating chamber. One to three ratio of male to female were applied in mating chambers. The females incubating eggs were removed from the mating chamber and placed in a conical- hatching tank for hatching. Subsequent treatments were similar to the previously described for the inbred population.

\section{Larval Rearing}

The larvae were then stocked into a 50- L conical- larval rearing tank at the density of 100 larvae per litre. Artemia nauplii were given exclusively for the first 12 days of rearing. A combination of artemia and artificial feed made from certain ingredients (New, 1990) were fed for the subsequent days until they reached post larval stage. Aeration was supplied continuously during the whole length of rearing period. 


\section{Examined Variables}

Effect of inbreeding on the larval performance was monitored using several parameters including, larval survival, larval growth, larval stage index (LSI), and dispersion rate of larval development. Observation of larval development was carried out every three days started from hatching to the last stage of metamorphosis (post larvae). It was performed by sampling 30 larvae and examined under light microscope for larval stage and growth. Larvae developmental stages were determined using formula of Uno \& Soo (1969) in Rahman et al. (2004) LSI = Si/ N (i = 1-11). Larval growth was measured using total length as a parameter.

\section{Data Analyses}

Comparison of larval performance between the inbred and the outbred populations was performed using descriptive and inferential statistics. Comparison of mean between two groups were performed using Kruskall- Wallis test and statistical significance was evaluated using bootstrapping method. Statistical analyses were performed using SYSTAT statistical package.

\section{RESULTS}

\section{Larval Survival}

Inbred populations performed much poorer than that of the outbred counterparts. The average survival rate of the outbred populations was about 30 percent, while that of the inbred was only about 6 percent, which is five times lower (Figure 1). This figure suggests that larval survival of the inbred populations really suffered from inbreeding depression.

\section{Larval Development}

Differed from the larval survival, development-associated traits including the rate of developmental stages, expressed in form of larval stage index (LSI), were moderately affected (Figure 2). The figure shows that during the first half of larval rearing period, both outbred and inbred populations performed a similar performance. Disparity started to emerge at day 15 and continued until the end of the larval rearing period. Started from day 15 , the outbred population undergone a faster developmental stage. It should be noted however, the disparity was not quite significant (Figure 2 ). These subtle differences were also observed in stage dispersion and growth traits.

Stage dispersion indicates variation of individuals within population. Comparison of stage dispersion between the outbred and inbred populations across five sampling dates did not show a consistent pattern. While at particular time points, namely at days 0,12 , and 24 , both populations showed a similar stage dispersion, they were different in the remaining sampling days. Stage dispersion of the outbred population was slightly higher than that of the inbred. At sampling day 6 for instance, the outbred population had four stages

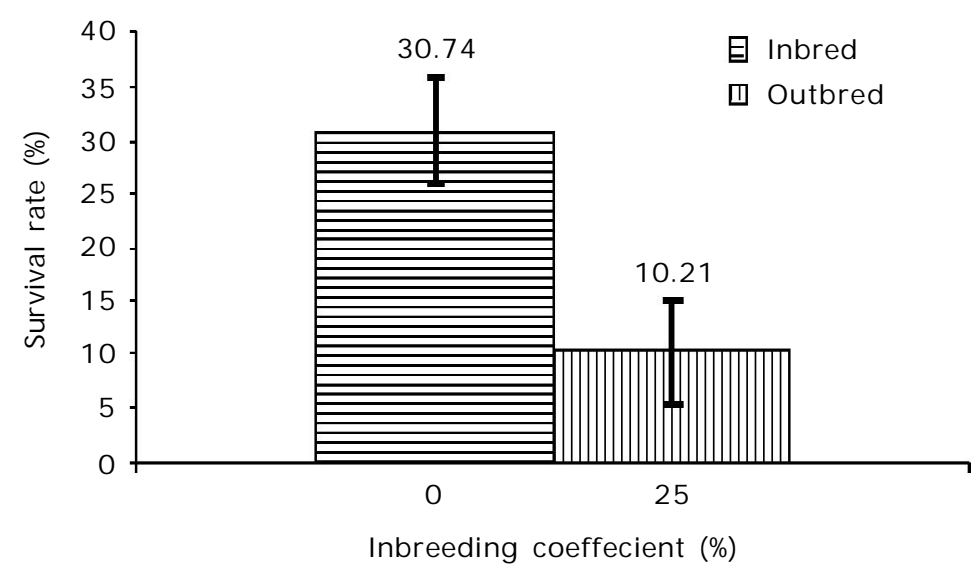

Figure 1. Comparison of larvae survival rate between the outbred and inbred populations. Different letter on top of each bar indicate significant difference $(\mathrm{P}<0.05)$ 
Indonesian Aquaculture Journal Vol.4 No.1, 2009

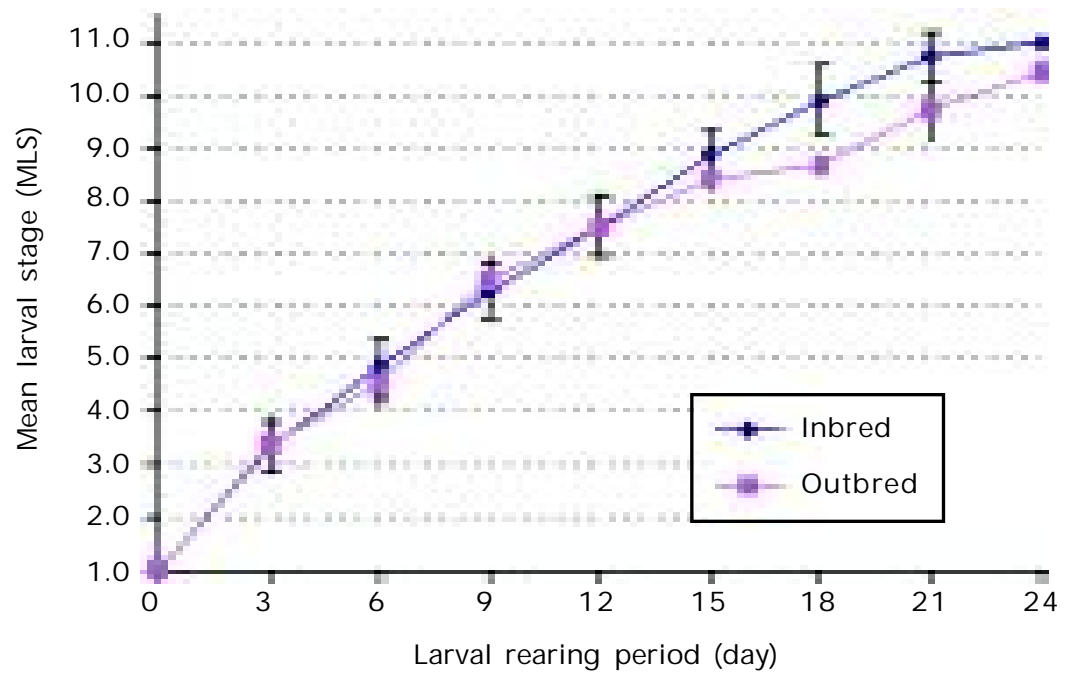

Figure 2. The rate of larval development within the inbred and outbred populations. Bar across the sampling points indicates standard error

while the inbred had only two stages. A similar pattern was also found in sampling at day 18 (Figure 3). This pattern suggests that individuals within the outbred population were more variable.

Growth performance at a particular developmental stage between the inbred and outbred populations (Figure 4), shows a slightly contrasting pattern. Across the first seven stages (LSI- 1 to LSI- 7), the growth of the outbred population was slightly higher that of the inbreds. The reverse pattern was observed from LSI- 8 onward. The growth of the inbred populations was slightly higher than that of the outbred. Despite these slight differences, statistical analysis suggest they were not significantly different $(P>0.05)$, meaning that in general, growth performance of both outbred and inbred populations was comparable.

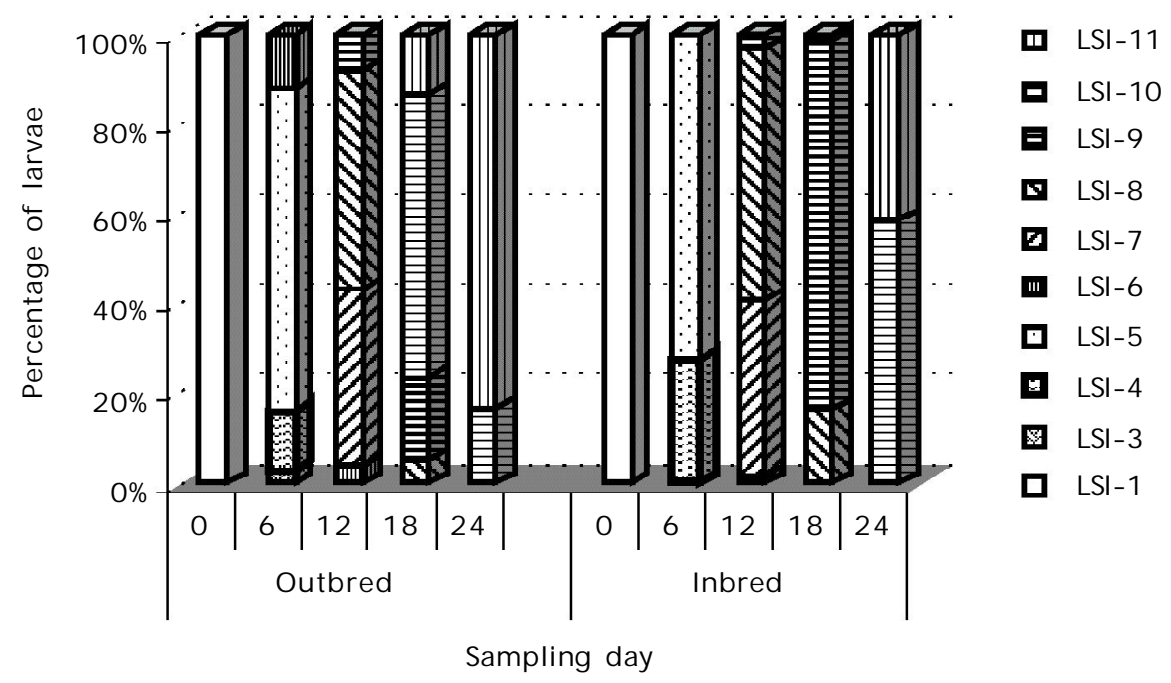

Figure 3. Dispersion of larval stage between the outbred and inbred populations 


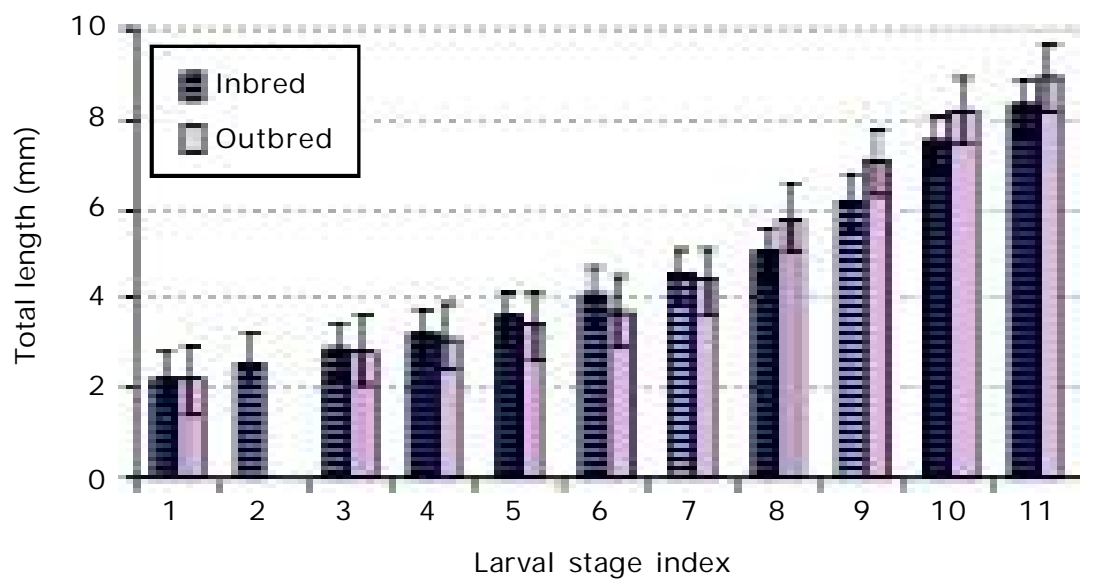

Figure 4. Growth of outbred and inbred populations at particular stage during larval development. Bar indicates standard error (SE)

\section{DISCUSSION}

Despite a general agreement among aquaculturists on the relationships between inbreeding and deterioration of performance (inbreeding depression), there have only been a few information with regards to the degree of inbreeding rate that decrease performance and the type of characters that the inbreeding rate influenced.

In relation to the degree of inbreeding coefficient, not all inbred populations performed poorer than that of the outbred counterparts. Previous studies suggested that inbreeding depression was started to emerge when it had reached particular level. In the Pacific abalone, Haliotis discuss hannai, inbreeding rate at $25 \%$ $(F=0.25)$ significantly affects larval growth and greatly reduces metamorphic success (Deng et al., 2005). In plant taxon, British Euphrasia sp., the rate of inbreeding coefficient has been correlated with flower size. Population with highest inbreeding coefficient $(>75 \%$ ) had the smallest flower size while that with lowest inbreeding coefficient $(<25 \%$ ) had the largest flower size (French et al., 2005). In the salmon, a series of inbreeding experiment studies indicated a negative correlation between inbreeding coefficient ranging from $20 \%$ to $60 \%$ and variety of phenotypic traits including growth, egg mass weight, hatchability, survival, and deformity (Kincaid, 1976; Kincaid, 1983).

Conversely, with estimated inbreeding coefficient at 3\% 10\% inbreeding depression in
Litopenaeus vannamei selectively bred for 11 generations was observed in only few first generations, then disappearing in the last generation. This phenomenon was considered due possibly to the elimination of deleterious alleles from the genetic pool (De Donato et al., 2005). Similarly, inbreeding did not appear to be a significant factor influencing reproductive performance of Standardbred horses (Cothran et al., 1984). It should be noted that inbreeding level at which the research conducted was less than $10 \%$

In relation to the trait affected by inbreeding, not all characters are affected by inbreeding at the same magnitude (Nakadate et al., 2003). Inbreeding depression seems to affect individual or population performance in a complex manner. Previous studies suggested that it has been associated and has been varied with the age, generation, and strain (Cothran et al., 1984).

Result observed in the current study, where only the larval survival significantly affected by inbreeding, was in line with typical results of inbreeding experiments described above. Low of survival in inbred populations may result from the act of deleterious alleles due to increased homozygosity, as had been occurred with L. vanamei breeding program in the early generations (De Donato et al., 2005). Under this scenario, individuals bearing deleterious alleles were purged from the population leading to a lower survival. Molecular investigation using a variety of molecular 
markers, particularly microsatellites, could be conducted to confirm whether this is the case.

A slightly higher growth of inbred population observed at stage 8 onward, was likely associated with different environmental conditions. High mortality occurred during previous days resulted in a lower larval density in the larval rearing tanks. This allowed individuals to grow better due to less competition for resources (space and feed).

Lack of significant effect of inbreeding on other investigated traits such as the rate of developmental stage, stage dispersion and growth may be explained by at least two reasons. First, due to character specificity, inbreeding depression did not affect the abovementioned characters. This is line with the results of Nakadate (2003) who worked with Poecilia reticulata. He suggested that at inbreeding coefficient of $25 \%$ inbreeding depression occurred in only two out of six investigated traits, namely growth and salinity tolerance. Alternatively, age- specific of inbreeding depression may also in place. If the second situation is the case, it should be anticipated that inbreeding depression would be expressed in the later stages of animal life history. To gain information of these questions, further-continuing studies using populations produced from the current study as experimental animal is being undertaken.

\section{Practical Aquaculture Implications}

In a closed breeding system where supply of broodstock relies from captivity, inbreeding is something unavoidable. This particularly occurs under situation where a limited number of broodstock are used for fry production, a general breeding practice applied by many fish breeding farmers. Study on Indian major carp (Eknath \& Doyle, 1990) suggested that the use of broodstock number as low as 3 to 30 fish was potential to produce population with inbreeding rate of $3 \% 17 \%$ per year. This figure is quite alarming given that inbreeding coefficient as moderate as $10 \%$ has been shown to adversely affect several phenotypic performances. Hence, many breeding programs have set an estimate of $10 \%$ inbreeding coefficient as an allowed maximum limit (Tave, 1995; Tave, 1999). Considering that general breeding practices applied by freshwater prawn breeding farmers is more or less similar to that studied by Eknath \& Doyle (1990), in- breeding phenomena are also potential and have been experienced by fish farmers in Indonesia. In fact, this problem has often been discussed in many consultation meetings and they expect to obtain a quick solution.

Results emerged from the current study provide preliminary evidence that inbreeding problem really exists in freshwater breeding practice. The solution for this problem is actually quite simple, namely proper broodstock management. However, performing a proper broodstock management is not a simple task. It needs significant knowledge on genetic principles and the way to manage the genetic resources in a wise manner. In principle, inbreeding coefficient of a closed population can be controlled or minimized by applying the mating of unrelated individuals, an approach that requires pedigree information and individual tagging. Alternatively, it can also be controlled by applying the concept of effective breeding number $(\mathrm{Ne})$. This latter approach is based on the principle that the $\mathrm{Ne}$ is inversely correlated with inbreeding coefficient. The more the number of $\mathrm{Ne}$, the less inbreeding coefficient in population will be. Practical guidelines and a detailed explanation on how to conduct a proper broodstock management by taking those mentioned approaches into account, can be found in Tave (1999).

In aquaculture species, where broodstock derived from aquaculture system either from selective breeding program or from inadvertent practices, inbreeding is something that can not be avoided. Hence the key is not to avoid inbreeding from happening, but to manage that degree of inbreeding in farmed population to not exceed the level that deteriorates performance.

\section{Conclusion and Recommendation}

Inbreeding depression affected early larval performance of freshwater prawn in different magnitude. At inbreeding coefficient of 25 percent, larval survival was significantly affected. However, other traits associated with development including the rate of developmental stage, the rate of dispersion stage, and growth were not or less affected. Considering the importance of larval survival in hatchery operation, it is recommended to manage broodstock properly so that inbreeding coefficient in a hatchery population does not exceed the level that may deteriorate perfor- 
mance of larval survival. Additionally, further studies are also required to know how this inbred population will perform in nursery, growout, until they mature and reproduce. All these information will be useful to set up a design of genetically- safe breeding program.

\section{ACKNOWLEDEMENTS}

The author would like to thank technical staffs of Macrobrachium research group, specially to Tatang Rustandi for the preparation and maintenance of live material and Listio Darmawanto for data recording. The study was a part selective breeding program of giant freshwater prawn conducted at Research Institute for Freshwater Fish Breeding and Aquaculture, Sukamandi.

\section{REFERENCES}

Ahmed, N., Demaine, H. , \&Muir, J.F. 2008. Freshwater prawn farming in Bangladesh: history, present status and future prospects. Aquaculture Research, 39: 806-819.

Bart, A.N. \& Yen, P.T. 2003. Comparison of larval performance between Thai and Vietnamese freshwater giant prawn, Macrobrachium rosenbergii (de Man): A preliminary study. Aquaculture Research, 34: 1,453-1,458.

Cothran, E.G., MacCluer, J.W., Weitkamp, L.R., Pfennig, D.W., \&Boyce, A.J. 1984. Inbreeding and reproductive performance in standardbred horses. Journal of Her edity, 75: 220- 224.

De Donato, M., Manrique, R., Ramirez, R., Mayer, L., \& Howell, C. 2005. Mass selection and inbreeding effects on a cultivated strain of Penaeus (Litopenaeus) vannamei in Venezuela. Aquaculture, 247: 159- 167.

Deng, Y., Liu, X., Zhang, G., \& Guo, X. 2005. Inbreeding depression and maternal effects on early performance of Pacific abaIone. North American Journal of Aquaculture, 67: 231- 236.

Eknath, A.E. \&Doyle, R.W. 1990. Effective population size and rate of inbreeding in aquaculture of Indian major carps. Aquaculture, 85: 293- 305.
French, G.C., Ennos, R.A., Silverside, A.J., \& Hollingsworth, P.M. 2005. The relationship between flower size, inbreeding coefficient and inferred selfing rate in British Euphrasia species. Heredity, 94: 44- 51.

Kincaid, H.L. 1976. Effects of Inbreeding on Rainbow Trout Populations. Transactions of the American Fisheries Society, 105: 273- 280.

Kincaid, H.L. 1983. Inbreeding in fish populations used for aquaculture. Aquaculture, 33: 215- 227.

Nakadate, M., Shikano, T., \&Taniguchi, N. 2003. Inbreeding depression and heterosis in various quantitative traits of the guppy, Poecilia reticulata. Aquaculture, 220: 219226.

New, M.B. 1990. Freshwater prawn culture: a review. Aquaculture, 88: 99- 143.

New, M.B. 2002. Farming freshwater prawns $A$ manual for the culture of the giant river prawn (Macrobrachium rosenbergii). FAO Fisheries Technical Paper.

Osure, G.O. \& Phelps, R.P. 2006. Evaluation of reproductive performance and early growth of four strains of Nile tilapia (Oreochromis niloticus, L) with different histories of domestication. Aquaculture, 253: 485- 494.

Rahman, M.M., Wille, M., Cavalli, R.O., Sorgeloos, P., \& Clegg, J.S. 2004. Induced thermotolerance and stress resistance in larvae of the freshwater prawn, Macrobrachium rosenbergii (de Man, 1879). Aquaculture, 230: 569- 579.

Su, G.S., Liljedahl, L.E., \& Gall, G.A.E. 1996. Effects of inbreeding on growth and reproductive traits in rainbow trout (Oncorhynchus mykiss). Aquaculture, 142: 139- 148.

Tave, D. 1995. Selective breeding for medium sized farms FAO Fisheries Technical Paper. No. 352., Rome.

Tave, D. 1999. Inbreeding and broodstock management, Fisheries technical paper No.392, 392 ed. FAO, Rome, 122 pp.

Theodorou, K. \& Couvet, D. 2006. On the expected relationship between inbreeding, fitness, and extinction. Genetics Selection Evolution, 38: 371- 388. 